\title{
Treatment of Hypertension: A Review
}

\author{
Laxmi Narayan Goit ${ }^{*}$, Shaning Yang² \\ ${ }^{1}$ Department of Cardiology, The First Affiliated Hospital of Yangtze University, Jingzhou, China \\ ${ }^{2}$ Department of Cardiology, Clinical College of Yangtze University \& The First Affiliated Hospital to Yangtze University, \\ Jingzhou, China \\ Email: ^laxmi_goit@hotmail.com, 1966157381@qq.com
}

How to cite this paper: Goit, L.N. and Yang, S.N. (2019) Treatment of Hypertension: A Review. Yangtze Medicine, 3, 101-123. https://doi.org/10.4236/ym.2019.32011

Received: October 8, 2018

Accepted: March 19, 2019

Published: March 22, 2019

Copyright (c) 2019 by author(s) and Scientific Research Publishing Inc. This work is licensed under the Creative Commons Attribution International License (CC BY 4.0).

http://creativecommons.org/licenses/by/4.0/

\begin{abstract}
Hypertension is the most common modifiable risk factor for death and disability including stroke, accelerated coronary and systemic atherosclerosis, heart failure, chronic kidney disease, lowering the BP with antihypertensive drugs, and reducing the target organ damage and prevalence of the occurrence of cardiovascular disease. According to the 2017 American college of cardiology (ACC)/American heart association (AHA) hypertension guidelines hypertension is defined as systolic $\mathrm{BP}$ is $\geq 130 \mathrm{mmHg}$ or diastolic $\mathrm{BP}$ is $\geq 80 \mathrm{mmHg}$. BP should be lower than $130 / 80 \mathrm{mmHg}$ in patient with $\mathrm{CHD}$, $\mathrm{CHF}$, after renal transplantation, diabetes mellitus and stroke. Recommended lifestyle modification included restriction of dietary sodium intake, weight loss if patient is overweight, regular exercise, moderate alcohol intake and increase consumption of potassium rich foods. The initial antihypertensive agent should be generally selected from one of the following four classes-thiazide diuretics, ACE inhibitors, ARBs, and calcium channel blockers, shown to reduce cardiovascular events. There are two interventional approaches-Renal Denervation and Baroreflex activation therapy, which are used in clinical practice for treatment of several treatment resistant hypertensions. Other interventional approaches are carotid body ablation and AVF placement but none of them prevent cardiovascular disease outcome or death in hypertensive patient.
\end{abstract}

\section{Keywords}

Target Blood Pressure, Antihypertensive Drugs Therapy, Renal Denervation, Carotid Body Ablation Therapy

\section{Introduction}

Hypertension is the elevation of systolic BP, diastolic BP, or both above normal levels, is common in developed and developing countries and increases in pre- 
valence with age increase. Although in recent years hypertension has been defined as a BP of 140/90 mmHg or more, the 2017 American College of Cardiology-American Heart Association (ACC-AHA) Hypertension Guideline adopted a lower threshold, in which hypertension is defined as a systolic BP of 130 $\mathrm{mmHg}$ or more or a diastolic BP of $80 \mathrm{mmHg}$ or more [1]. Among adults in the United States, the overall prevalence of hypertension was $31.9 \%$ under the previous definition (blood pressure, $\geq 140 / 90 \mathrm{mmHg}$ ) and is $45.6 \%$ according to the 2017 ACC/AHA guideline definition (BP $\geq 130 / 80 \mathrm{mmHg}$ ) [2]. Similarly, the rate of hypertension control was $61.0 \%$ among those receiving treatment at a target of less than $140 / 90 \mathrm{mmHg}$ but only $46.6 \%$ at a target of less than $130 / 80$ $\mathrm{mmHg}[2]$.

Worldwide, hypertension is the leading modifiable and major risk factor for $\mathrm{CV}$ events and mortality in adult [3] [4]. Hypertension is present in $69 \%$ of adults with a first MI [4], in $77 \%$ of adults with a first stroke [4], in $74 \%$ of adults with HF [4], and in $60 \%$ of older adults with PAD [5]. Hypertension is also a major risk factor for development of SCD, a dissecting aortic aneurysm, angina pectoris, $\mathrm{LVH}$, thoracic and abdominal aortic aneurysms, CKD, atrial fibrillation, DM, vascular dementia and ophthalmologic disease [6]. The increased risk associated with BP elevation can be greatly reduced by treatment with antihypertensive drugs that lower both BP and related target organ damage. A total of 69 drugs in 15 different classes, many of which are also available in single pill combinations, have been approved for the treatment of hypertension in the United States. Despite this treatment options, an estimated $10 \%$ to $15 \%$ of the general $\mathrm{RH}$, is defined as uncontrolled $\mathrm{BP}$ on $\geq 3$ antihypertensive drugs of different classes, in which one of them is diuretic, at optimal doses or requiring $\geq 4$ drug to control blood pressure [7] [8] and causes of $\mathrm{RH}$ are primarily hyperaldosteronism, Renovascular disease, Cushing syndrome and Pheochromocytoma. In addition, $\approx 0.5 \%$ of hypertensive patients have refractory hypertension, defined as uncontrolled BP on $\geq 5$ drugs [9]. Recent drug monitoring studies have revealed no adherence to BP lowering therapy in $25 \%$ to $65 \%$ of patients with apparent TRH [10] [11] [12] [13]. In $24 \%$ to $34.5 \%$ of these individuals, who were prescribed 3 - 5 antihypertensive medications, no antihypertensive medication was detected in blood or urine samples.

A systematic review and Meta analysis included 123 randomized studies of antihypertensive drug therapy in 613,815 individuals [14]. The review found that every $10 \mathrm{~mm}$ of $\mathrm{Hg}$ decrease in SBP significantly decreased major CV event by $20 \%$, CHD by $17 \%$, stroke by $27 \%$, and HF by $28 \%$, which in all populations studied reduced all causes of mortality by 13\% [14]. SPRINT (systolic BP intervention trial) randomized 9361 adults to a systolic BP goal of $<120 \mathrm{~mm}$ of $\mathrm{Hg}$ or $<140 \mathrm{~mm}$ of $\mathrm{Hg}$ [15]. These patients have mean age of 67.9 years, systolic BP 130 - $180 \mathrm{~mm}$ of $\mathrm{Hg}$ and increased CV risk, no DM, history of stroke, or asymptomatic HF within the past 6 months, left ventricular ejection fraction $<35 \%$, and estimated glomerular filtration rate $<20 \mathrm{ml} / \mathrm{min} / 1.73 \mathrm{~m}^{2}$ [15]. At 3.26 years follow up BP treatment reduced the primary composite outcome of MI, stroke, HF, 
or death from CV causes by $25 \%$, all causes mortality by $27 \%$, HF by $38 \%$, CV death by $43 \%$ and primary composite outcome or death by $22 \%$ [15].

\section{Blood Pressure Goals Recommended by Different Guidelines}

The 2013 Eight Joint National Committee (JNC 8) guidelines for management of hypertension recommended lowering BP to $<150 / 90 \mathrm{mmHg}$ in adult aged $\geq 60$ years without diabetes mellitus or Chronic kidney disease and $<140 / 90 \mathrm{mmHg}$ in adult with diabetes mellitus chronic kidney disease [16]. The minority view from JNC 8 recommended that the BP goal in adults aged $<80$ years with hypertension without DM or CKD should be $<140 / 90 \mathrm{mmHg}$ [17]. The UK National Institute of health and Care Excellence (NICE) hypertension guideline, update in 2013 recommended lowering $\mathrm{BP}$ to $<140 / 90 \mathrm{mmHg}$ in aged $<80$ years [18]. These guidelines recommended lowering $\mathrm{BP}$ to $<150 / 90 \mathrm{mmHg}$ in adult aged $\geq 80$ years [18]. The 2014 international society of hypertension (ISH) guidelines recommended reducing $\mathrm{BP}$ to $<140 / 90 \mathrm{mmHg}$ in adult aged $\leq 80$ years [19]. These guidelines also recommended lowering $\mathrm{BP}$ to $<150 / 90 \mathrm{mmHg}$ in adult aged $\geq 80$ years with $\mathrm{BP} \geq 150 / 90 \mathrm{mmHg}$ unless these adult have $\mathrm{DM}$ or $\mathrm{CKD}$ in which case a target goal of $<140 / 90 \mathrm{mmHg}$ should be considered [19].

The ACC (American college of cardiology)/AHA (American heart Association)/ASH (American society of hypertension) 2015 guidelines on treatment of hypertension in patient with CHD recommended that target BP should be < $140 / 90 \mathrm{mmHg}$ in adult with CHD and ACS if aged $\leq 80$ years but $<150 / 90$ $\mathrm{mmHg}$ if they are aged $\geq 80$ years [20]. These guidelines also stated that lowering $\mathrm{BP}$ to $<130 / 80 \mathrm{mmHg}$ in adult with CHD who have had a MI, stroke, TIA, carotid artery disease, abdominal aortic aneurysm.

The National Heart Foundation (NHF) of Australia 2016 hypertension guidelines state that in patient with uncomplicated hypertension target BP should be $<140 / 90 \mathrm{mmHg}$ or lower [21]. In selected high CV risk individual target systolic BP should be $<120 \mathrm{mmHg}$ can improve CV outcome [21]. These adults should have closely monitored to identify treatment related adverse effect, including hypotension, syncope, electrolyte imbalance and acute kidney injury [21].

The 2017 American college of physicians (ACP)/American Academy of Family physician (AAFP) hypertension guidelines give three recommendations [22].

1) Adult aged $\geq 60$ years with systolic blood pressure $\geq 150 \mathrm{mmHg}$ should have systolic BP reduced to $<150 \mathrm{mmHg}$ to reduce the risk of mortality, stroke, and cardiovascular event.

2) Adult aged $\geq 60$ years with history of stroke or Transient ischemic attack should have reduced systolic BP to $<140 \mathrm{mmHg}$ to decrease the risk of recurrent stroke.

3) Adult aged $\geq 60$ years at high cardiovascular risk based on individual assessment should have target systolic BP reduced to $<140 \mathrm{mmHg}$ to reduce their risk for stroke and cardiovascular event.

The 2017 ACC/AHA hypertension guidelines stated that normal BP is 
$<120 / 80 \mathrm{mmHg}$ [23] as shown in Table 1. Elevated BP was defined as systolic BP is $120-129 \mathrm{mmHg}$ with diastolic $\mathrm{BP}$ is $<80 \mathrm{mmHg}$ and should be treated with life style measure [24]. Stage 1 hypertension is systolic BP is $130-139 \mathrm{mmHg}$ or diastolic BP is $80-89 \mathrm{mmHg}$ and Stage 2 hypertension is systolic BP $\geq 140$ $\mathrm{mmHg}$ or diastolic BP is $\geq 90 \mathrm{mmHg}$.

The 2017 ACC/AHA hypertension guideline recommended lifestyle measure plus $\mathrm{BP}$ lowering drug for secondary prevention of recurrent $\mathrm{CV}$ event in adult with clinical $\mathrm{CV}$ disease-CHD, $\mathrm{CHF}$ and stroke and average systolic $\mathrm{BP}$ is $\geq 130$ $\mathrm{mmHg}$ or average diastolic BP is $\geq 80 \mathrm{mmHg}$ [1] [14] [25] [26]. These guidelines recommended lifestyle measure plus BP lowering drug for primary prevention of $\mathrm{CV}$ disease in adult with an estimated 10 years risk of atherosclerotic CVD (ASCVD) $\geq 10 \%$ [27] and average systolic BP is $\geq 130 \mathrm{mmHg}$ or an average diastolic BP is $\geq 80 \mathrm{mmHg}$ [1] [15] [28] [29]. These guidelines recommended lifestyle measure plus BP lowering drug for primary prevention of $\mathrm{CV}$ in adult with estimated 10 years risk of ASCVD $<10 \%$ [27] with an average systolic BP is $\geq 140$ $\mathrm{mmHg}$ or an average diastolic BP is $\geq 90 \mathrm{mmHg}$ [1] [29] [30].

The 2017 ACC/AHA hypertension guidelines recommended lowering BP to $<130 / 80 \mathrm{mmHg}$ in adult with CHD [1] [15] [26] [28] [31], CHF with reduced left ventricular ejection fraction [1] [32], CHF with preserved left ventricular ejection fraction [1] [32], CKD [1] [33], after renal transplantation [1], adult with Lacunars stroke [1] [34], PAD [1] [25], DM [1] [35] [36], for secondary prevention of stroke [1] [37] and ambulatory community dwelling adult aged 65 year [1] [15] [28].

\section{Evaluation of Patient}

The first step is to confirm the diagnosis of hypertension. The guideline recommended at least two BP measurement on at least two occasions with use of standard measurement technique, validated equipment, including cuff of correct size [1]. The 2017 ACC/AHA hypertension guideline recommended the use of ambulatory BP measurement or home BP monitoring for the diagnosis of white coat hypertension or masked hypertension [1]. White coat hypertension is diagnosed when BP is increased in hospital or clinic but normal in ambulatory BP monitoring technique or home BP monitoring. Masked hypertension is diagnosed

Table 1. Classification of BP in adult according to ACC/AHA 2017 hypertension guidelines [23].

\begin{tabular}{cc}
\hline Blood pressure Category & Definition \\
\hline Normal BP & Systolic BP $<120 \mathrm{mmHg}$ and diastolic $\mathrm{BP}<80 \mathrm{~mm} \mathrm{Hg}$. \\
Elevated BP & Systolic BP $120-129 \mathrm{mmHg}$ and diastolic $\mathrm{BP}<80 \mathrm{~mm} \mathrm{Hg}$. \\
Hypertension: & \\
Stage-1 & Systolic BP $130-139 \mathrm{mmHg}$ and diastolic BP $80-89 \mathrm{~mm} \mathrm{Hg}$. \\
Stage-2 & Systolic BP $\geq 140 \mathrm{mmHg}$ and diastolic BP $\geq 90 \mathrm{~mm} \mathrm{Hg}$. \\
\hline
\end{tabular}

BP: Blood pressure. 
if $\mathrm{BP}$ is normal in hospital or clinic but increased in ambulatory BP monitoring technique or in home BP monitoring. Ambulatory blood BP monitoring can measure the $\mathrm{BP}$ while patient perform normal daily activities and can measure mean BP during the entire monitoring periods, means BP during day and night time and diagnosed the symptomatic hypotension [1]. Once the diagnosis is confirmed, a complete history should be taken to assess the coexisting condition and contributing factors including lifestyle, CV risk factors associated with hypertension and feature suggest secondary causes of hypertension. On examination if presence of carotid, abdominal or femoral bruits increase the possibility of renal artery stenosis. Diminished femoral pulses or a discrepancy between arm and thigh blood pressure suggests aortic coarctation or significant aortoiliac disease. Cushing disease is suggested by abdominal striae, moon faces or prominent interscapular fat deposition. A gradual rise in BP that associated with weight gain with positive family history suggests primary hypertension where as several or RH with target organ damage suggests secondary hypertension and common causes of secondary hypertension listed in Table 2. Initial laboratory investigation shown in Table 3, should assess for coexisting condition that may affect patient response to medication and assess for target organ damage.

Table 2. Common causes of secondary hypertension [38].

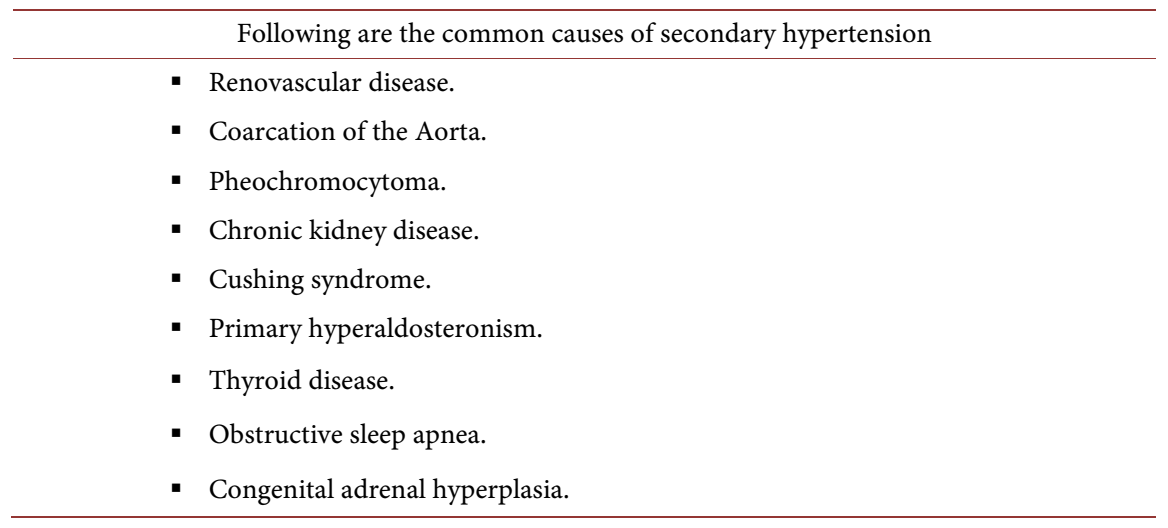

Table 3. Basic investigation of hypertension [40] [41] [42] [43] [44].

Following are the basic investigation of hypertension:

- Complete blood count-TLC, DLC, Hb \%, RBC

- Renal function test-Blood urea, serum creatinine, potassium, Sodium, calcium, uric acid

- Blood sugar level

- Urinalysis

- Lipid profile

- Thyroid function test

- Electrocardiography

- Urine albumin to creatinine ratio

- Measure plasma aldosterone/Renin ratio

- Measurement of 24 hours urinary metanephrines. 
The aldosterone/renin ratio is effective screening test for primary aldosteronism [39]. Collection of urine of 24 hours during ingestion of the patient normal diet can be helpful in estimating dietary sodium and potassium intake, calculating creatinine clearance and measuring aldosterone excretion. Measurement of 24 hours urinary metanephrines or plasma metanephrines is an effective screen for patients in whom Pheochromocytoma is suspected [40]. Imaging for renal artery stenosis should be reserved for patient in whom there is an increased level of suspicion. Regarding target organ damage, 24 hour urinary albumin excretion and left ventricular mass index are increased in resistant hypertension [41].

\section{Treatment of Hypertension}

The treatment of hypertension consists of both nonpharmacologic and pharmacological approaches. Treatment decision depends on whether there is pre-existing $\mathrm{CV}, \mathrm{DM}$, and CKD. For patient with stage one hypertension and without these conditions, the 2017 AHA/ACC guideline recommended calculation of 10 years risk of cardiovascular disease. If the risk is less than $10 \%$, it is reasonable to implementation life style modification alone for 3 - 6 month. For stage 2 hypertension with pre-existing like DM, CKD and 10 years risk of CV event is $10 \%$ or high both life style modification and medication is recommended.

\subsection{Nonpharmacological Treatment}

Following are the nonpharmacologic way to treatment of hypertensions.

\subsubsection{Dietary Salt Restriction}

The restriction dietary sodium intake is below $1500 \mathrm{mg}$ per day [45] [46]. The benefit of dietary salt reduction is well documented in general hypertensive patient in whom associated with reduction of 5 to $10 \mathrm{mmHg}$ in Systolic BP and 2 to $6 \mathrm{mmHg}$ diastolic BP.

\subsubsection{Weight Loss}

Weight loss has a clear benefit in term of reducing of blood pressure and also reduce the number of prescribed medicine so weight loss if the patient is overweight or obese [47]. Long term weight loss studies have indicated that $10 \mathrm{~kg}$ weight loss is associated with average reduction of systolic BP $6 \mathrm{mmHg}$ and diastolic $\mathrm{BP}$ is $4.6 \mathrm{mmHg}$.

\subsubsection{Physical Activity}

The regular aerobic exercise produced average reduction of systolic BP $4 \mathrm{mmHg}$ and $3 \mathrm{mmHg}$ in diastolic BP. So patient is advice for aerobic or resistance exercise for 90 to 150 minute per week [48] [49]. So all patient of hypertension encouraged to do exercise.

\subsubsection{Moderate Alcohol Intake}

All patient of hypertension advised for moderate of alcohol intake $-\leq 2$ drinks daily for men and $\leq 1$ drink per day for woman will reduce systolic BP by 3 to 8 
$\mathrm{mmHg}$ and diastolic BP by 1 to $4 \mathrm{mmHg}$ [50] [51].

\subsubsection{High Fiber and Low fat Diet}

Ingestion of diet rich in fruits and vegetable, potassium, magnesium, calcium, high in low fat diet and low in saturated fat that is dietary approach to stop hypertension (DASH) reduced systolic BP in hypertension patient by 11.4 $\mathrm{mmHg}$ and reduced diastolic BP by $5.5 \mathrm{mmHg}$ [52]. High amount of fruit and vegetables in diet not lower the BP but also improve endothelial function.

\subsubsection{Withdrawal of Interfering Medications}

Medicine that may interfere with BP control, mainly NSAIDS should be voided or if complete avoidance is difficult the lowest effective dose should be used. When initiating treatment of hypertension with these agents should monitored BP closely because adjustment to antihypertensive regimen may become necessary. Following medicine shown in Table 4 should be avoided during treatment of hypertension [42].

\subsection{Pharmacological Treatment}

The 2017 ACC/AHA guideline recommended initiation of anti hypertensive drug treatment with two first line drug from different classes, either as separate agent or in fixed dose combination and target BP should be less than 130/80 $\mathrm{mmHg}[1]$.

\section{Initial drug selection:}

The initial agent can be selected from one of the following four classes: Angiotensin converting enzyme inhibitors (ACE inhibitors), Angiotensin receptors blockers (ARBs), Calcium channel blockers (CCBs) and thiazide type of diuretics and each class of antihypertensive drugs reduces CV events [53]. A meta-analysis of 147 randomized controlled trials of 464,000 patients with hypertension demonstrated that except for major effect of beta blockers administered after MI reduced CAD event and calcium channel blockers reduced stroke-all major antihypertensive drug class (Diuretic, Angiotensin converting enzyme inhibitors, Angiotensin receptors blockers, beta blockers and calcium channel blockers) causes reduction in CAD event and stroke for reduction in BP [54]. The 2011 ACC/AHA hypertension guideline state that choice of antihypertensive drugs in the treatment of adult hypertension depend on efficacy, tolerability, presence of specific comorbities and cost [6].

Table 4. Medicines avoided during treatment of hypertension [42].

\begin{tabular}{l} 
Following are the medicines during treatment of hypertension: \\
\hline - Non steroidal anti-inflammatory drugs \\
- Oral contraceptives pills \\
- Corticosteroids \\
- Tricycle antidepressant drugs \\
- Monoamine oxidase inhibitors
\end{tabular}


The 2011 ACC/AHA hypertension guidelines recommended that elderly patient with primary hypertension may be treated with Diuretics, ACE inhibitors, ARBs, Beta blockers, and calcium channel blockers (CCBs) [6].

The 2013 JNC 8 guidelines for management of hypertension recommended that non black adult with primary hypertension is treated with diuretics, Angiotensin converting enzyme inhibitors, Angiotensin receptors blockers and calcium channel blockers [16].

The 2014 American society of hypertension (ASH)/International society of hypertension (ISH) guideline recommended that non black adult with primary hypertension aged $<60$ years should be treated with Angiotensin converting enzyme inhibitors(ACE inhibitors) or Angiotensin receptors blockers (ARBs) [19]. These guidelines recommended that non black adult with age $\geq 60$ years with primary hypertension is treated with diuretics, CCBs, ACE inhibitors or ARBs [19]. These guidelines also recommended that black adult with primary hypertension is treated calcium channel blockers or thiazide diuretics [19].

The 2017 American college of cardiology (ACC)/American heart association (AHA) hypertension guidelines a regarding antihypertensive drug treatment for primary hypertension and secondary hypertension as follow [1]:

\subsubsection{White and Their Non Blacks Aged $<60$ Years with Primary Hypertension}

The first choice of antihypertensive drug should be ACE inhibitors or ARBs and second choice is diuretic or calcium channel blockers and if third drug is needed then combination of ACE inhibitors or ARBs plus thiazide diuretic plus calcium channel blockers is given [1] [19].

\subsubsection{White and Other Non Blacks Aged $\geq 60$ Years with Primary Hypertension}

The first choice of antihypertensive drug should be thiazide diuretics or CCBs and second choice is ACE inhibitors or ARBs and if third antihypertensive is needed then combination of thiazide diuretic plus CCB plus ACE inhibitors OR ARB [1] [19].

\subsubsection{Blacks with Primary Hypertension}

The first antihypertensive drug should be thiazide diuretic or CCBs and if third antihypertensive is needed then combination of thiazide diuretic plus CCBs plus ACE inhibitors or ARB should be given [1] [19].

\subsubsection{Stable Coronary Heart Disease with Hypertension}

Patient with stable CAD and hypertension is treated with beta blockers plus ACEs inhibitors or ARBs and if third antihypertensive drug is necessary then combination of beta blockers plus ACE inhibitors or ARB plus thiazide diuretics or CCBs should be administered [1] [20] [54] [55].

\subsubsection{Heart Failure with Reduced Left Ventricular Ejection Fraction and Hypertension}

Patient with HF with reduced left ventricular ejection fraction and hypertension 
is treated with beta blockers (carvedilol, metoprolol, bisoprolol) plus ACEs inhibitors or ARBs plus diuretics [1] [32] [56] [57] [58] [59] [60].

\subsubsection{Heart Failure with Preserved Left Ventricular Ejection Fraction}

Patient with HF and preserved left ventricular ejection fraction with hypertension should have volume over load so treated with diuretics and hypertension is treated with beta blockers plus ACEs inhibitors or ARSs plus mineralocorticoid receptors antagonist [1] [32] [61] [62].

\subsubsection{Chronic Kidney Disease with Heart Failure}

Patient with hypertension and CKD stage- 3 or higher or stage-1 or stage- 2 with albuminuria $\geq 300 \mathrm{mg} /$ day should be treated with ACEs inhibitors to slow progression of CKD [1] [33] [63] [64] [65]. If patients don't tolerate ACEs inhibitors, patients should be treated with ARBs [1]. Adult with stage 1 or 2 CKD without Albuminuria should be treated with first line antihypertensive drug [1]. If three antihypertensive needed then gives ACE inhibitors or ARB plus thiazide diuretic plus CCBs. After kidney transplantation, hypertension is treated with CCBs to improve glomerular filtration rate and kidney survival [1] [66].

\subsubsection{Stroke or Transient Ischemic Attack with Hypertension}

Hypertensive patient with stroke or Transient ischemic attack should be treated with thiazide diuretic or ACEs inhibitors or ARBs [1] [67] [68] [69]. If third antihypertensive drug is needed then give thiazide diuretic plus ACE inhibitors or ARBs plus CCB should added.

\subsubsection{Peripheral Arterial Disease and Hypertension}

Patient with PAD and hypertension should be treated with any of the first line antihypertensive drug that is Diuretics, ACEs inhibitors, ARBs, CCBs and beta blockers similar to patient without peripheral arterial disease [1] [70].

\subsubsection{Hypertension and Diabetes Mellitus}

In patient with hypertension and diabetes mellitus should be treated with ACEs inhibitors or ARBs, CCBs and thiazide diuretic [1] [35] [71]. If patients with diabetes mellitus, hypertension and persistent albuminuria, initial treatment with ACEs Inhibitors or ARBs [1] [72] [73].

\subsubsection{Thoracic Aortic Aneurysm and Hypertension}

Beta blockers are preferred antihypertensive drug for patient with hypertension and thoracic aortic aneurysm [25]. Beta blockers are also associated with increase improved survival in aortic dissection [1] [74].

\subsubsection{Hypertension and Pregnancy}

Women with hypertension who become pregnant should not treat with ACEs inhibitors, ARBs, direct renin inhibitors or atenolol [1] [75] [76] [77]. Methyldopa, Hydralazine, Nifedipine, and Labetalol is a drug of choice in patient with hypertension and pregnancy [1] [78]. 


\subsubsection{Resistant Hypertension}

Treatment of RH included detection and treatment of secondary hypertension, use of life style measure and treat obesity and other comorbidities [1] [24]. If fourth antihypertensive drug is required to control blood pressure then give mineral ocorticoids receptors antagonist that is spironolactone in the therapeutic regimen [79].

\section{New Approach for Treatment of Hypertension}

\subsection{Part 1: New Drugs for Treatment of Hypertension}

\subsubsection{Antialdosterone Agent}

Aldosterone is a mineralocorticoid that regulates electrolyte and water balance in the body and when aldosterone level elevated in the body can contribute to the development of hypertension and other disease including myocardial hypertrophy fibrosis of myocardium and heart failure [80]. The aldosterone act on mineralocorticoid receptor in the cortical collecting duct of the nephron and mineralocorticoid receptors stimulate expression of sodium channels, resulting in increased sodium and water reabsorption and potassium loss, lead to a volume expanded form of hypertension. Aldosterone is synthesized from 11-deoxycorticosteronein the zonaglomerulosa of adrenal cortex through the action of mitochondrial cytochrome P450 enzyme, aldosterone synthase which is encoded by the CYP11B2 gene [81].

\section{Mineralocorticoid Receptor Antagonists}

Mineralocorticoid receptor antagonist, Spironolactone monotherapy has modest BP lowering efficacy and recent used as add on therapy in patients with RH. Spironolactone used has been limited due to lack of selectivity for the mineralocorticoid receptor at higher dose because it's structural similarity to progesterone resulting significant progestogenic and antiandrogenicactivity leading to adverse effect in both men and women. The more selective mineralocorticoid receptor antagonist is eplerenone has lack of antiandrogenic effect of spironolactone but it is less potent and short half life $(3-4 \mathrm{~h})$ lead to reduced antihypertensive efficacy and requirement for twice daily dose. The optimization of MRA activity of dihydropyridine compound led to development of BAY 94 886 (finerenone), nonsteroidal MRA that has greater selectivity than spironolactone for the MR over other steroid hormone receptors, greater affinity than Eplerenone for MR and no effect on the L-type calcium channel [82] [83]. Finerenone has greater cardiac activity and improve myocardial function without affecting sodium potassium homeostasis in kidney. In preclinical model of hypertension related heart failure and renal dysfunction, finerenone work as greater cardio renal target organ protection than steroidal mineralocorticoid receptor antagonist [84].

\section{Aldosterone Synthase Inhibitors}

LCI699, the first orally active aldosterone synthase inhibitors which decrease plasma and urine aldosterone concentration, increase plasma renin activity and prevent the target organ damage in animal models of hypertension and heart 
failure [85] [86], Similar effects on aldosterone and renin level seen in healthy humans [87] and in hypertensive patients [88] [89]. The first randomized double-blind, placebo-controlled trial of LCI699, performed in 524 patients with primary hypertension, compared the efficacy and safety of different doses of LCI699 with eplerenone [89]. All doses of LCI699 produced significant reductions in office systolic BP that were no inferior to those seen with eplerenone. Plasma aldosterone levels were suppressed with LCI699 and increased with eplerenone, both agents were well tolerated.

\subsubsection{Vasopeptidase Inhibitors}

The zinc metalloprotease neprilysin is a therapeutic target for hypertension and other forms of Cardiovascular disease because it degrades the natriuretic peptides atrial natriuretic peptide (ANP), B type natriuretic peptide (BNP), and urodilatin [90] and increase in circulating natriuretic peptide levels that results from neprilysin inhibition leads to natriuresis, vasodilatation, renin-Angiotensin-aldosterone system inhibition, reduced sympathetic drive, and antiproliferative and antihypertrophic effects on heart.

\section{Natriuretic Peptide Receptor Agonist}

Natriuretic peptide receptor agonists are developed as alternative approach to inhibiting the degradation of endogenous natriuretic peptides for the treatment of heart failure and refractory or RH. The natriuretic peptide receptor A (NPR-A) agonist PL-3994 is a synthetic molecule that contains an amino acid mimetic and has reduced affinity for the natriuretic peptide clearance receptor (NPR-C) and increased resistance to neprilysin, resulting in a prolonged half-life after subcutaneous administration [91]. A phase I trial of a single subcutaneous dose of PL-3994 in healthy volunteers showed increased natriuresis and diuresis and reduction in systemic BP compared with placebo. A phase II trial in volunteers with hypertension who were receiving $\geq 1$ antihypertensive medications demonstrated a reduction in systemic BP compared with placebo. In particular, PL-3994 appeared to act synergistically with ACE inhibitors, suggesting that it could be administered as an adjunct to standard therapy in patients with refractory or RH or HF.

\subsubsection{Dopamine $\beta$-Hydroxylase Inhibitor}

Dopamine $\beta$-hydroxylase the enzyme that catalyzes the hydroxylation of dopamine to form noradrenaline in the sympathetic nervous system, is a therapeutic target for treatment of hypertension and other cardiovascular disorders characterized by sympathetic activation in HF. Inhibition of Dopamine $\beta$-hydroxylase offers theoretical advantages over adrenergic receptor blockade: 1) it causes gradual sympathetic slowdown; 2) it increases dopamine availability, thus causing renal vasodilatation, natriuresis, and diuresis. First, second, and early third generations $\mathrm{D} \beta \mathrm{H}$ inhibitors, for example, disulfiram, fusaric acid, and nepicastat, either lacked potency or selectivity for $\mathrm{D} \beta \mathrm{H}$ or caused severe CNS-related adverse effects and thus were not clinically useful. Etamicastatis potent and revers- 
ible inhibitors of Dopamine $\beta$-hydroxylase that not cross the blood brain barriers thus selective for peripheral Dopamine $\beta$-hydroxylase when given orally. Studies in healthy men and men with mild to moderate hypertension showed good tolerability and significant dose-dependent decreases in 24-h ambulatory BP [92].

\subsection{Part 2: Interventional Approach for Treatment of Hypertension}

For the management of arterial hypertension, interventional strategies are mentioned as a therapeutic option for several treatment resistant hypertensions.

\subsubsection{Renal Denervation}

This is rapidly growing research field with numerous published papers dealing with RDN. Increased sympathetic activity plays an important role in development, maintenance and acceleration of arterial hypertension [93] [94]. Activation of efferent sympathetic nerve in kidney stimulate renin release, enhance tubular reabsorption of sodium and water and decrease renal blood flow resulting blood volume will increase and BP raised. Renal sympathetic outflow is activated in essential hypertension, and basically the aim of the treatment is, by endovascular technique, to interrupt this activation causing BP reduction. Catheter based Renal Denervation has been introduced as a new interventional approach targeting the sympathetic nerve activity. The ablation of renal sympathetic nerves with a radiofrequency catheter has been evaluated with great enthusiasm. The multielectrode Denervation system available now allow 4 ablation to be performed with single short treatment time for each renal artery and provide more complete ablations. A randomized study (Symplicity HTN-2 trial) enrolled 106 patients and demonstrated a mean reduction of 32/12 mmHg at 6 months in office systolic and diastolic BP, respectively [95] and this effect was maintained after 2 years of follow-up. Nevertheless, the results were based on office BP where as Ambulatory BP monitoring data were available only in a small subgroup, showing a less impressive BP reduction (11/7 mmHg in 24-h BP) after 6 months [95]. Moreover, it is not clear if BP reduction was sustained over long-term follow-up [96]. The renal sympathetic Denervation shall be reserved to more severe RH patient, in whom ambulatory BP remain uncontrolled despite using four or more antihypertensive drug including mineralocorticoid receptors blockers. Other effects of renal Denervation beyond the BP reduction include improvement of glucose metabolism, beneficial effect on end organ damage, for example, LVH, arterial stiffness, and albuminuria and improvement in functional status in patient with congestive HF.

\subsubsection{Baroreflex Activation Therapy}

Baroreflex activation therapy is surgically implantable device, work by electrical stimulating carotid sinus baroreceptors, causes reduction in sympathetic response and consequently BP reduction. The rheos pivotal trial [97] was a doub- 
leblind, randomized, placebo-controlled device trial conducted in hypertension patients. There was a mean reduction in office systolic BP of up to $35 \mathrm{mmHg}$ after 12 months, and over $50 \%$ of subjects achieved systolic BP control. This effect was sustained over longer follow-up of 22 - 53 months. It is important to note that this trial did not evaluate ambulatory BPs, just office BP reduction. A similar trial conducted in Europe (DEBuT-Device Based Therapy) evaluated ambulatory BP [98]. After 12 months, office systolic BP was reduced in $30 \mathrm{mmHg}$, whereas ambulatory systolic BP showed a mean reduction of $13 \mathrm{mmHg}$. Therefore, the future of this procedure is uncertain and some dought are not completely clarified yet. More investigation is required about the long term safety and to evaluate whether the reduction in ambulatory BP with addition of some new drugs.

\subsubsection{Carotid Body Ablation}

Carotid body ablation Studies in animal model and human subject [95] revealed enhanced carotid body sensitivity in hypertension but mechanism of abnormality is not known. In a small, randomized, crossover, placebo-controlled study, deactivation of $\mathrm{CB}$ chemoreceptor's by hyperoxia (respiration with 100\% oxygen) attenuated the enhanced muscle sympathetic nerve activity in untreated hypertensive men, but no change was observed in controls [96]. It has also been shown that hyperoxia decreases BP acutely in patients with hypertension, but not in normotensive controls. These data point to a potential pathogenetic role of tonic chemoreceptor drive in the development of sympathetic over activity in hypertension [99]. Surgical removal of carotid body has been performed in human for reason other than hypertension (bronchial asthma, COPD). A BP fall from 170 to $130 \mathrm{mmHg}$ was observed after 5 day of removal of carotid body and sustained for 6 month after bilateral carotid body surgery in hypertension patient where as no effect on BP seen in normotensive patient. To data no study addressing the effect of unilateral or bilateral carotid body resection for hypertension in human has being completed but first in man studies are ongoing.

\subsubsection{Arteriovenous Fistula}

The self expanding device creates a $4 \mathrm{~mm}$ AVF between iliac artery and vein, generating a sustained calibrated shunt volume $800 \mathrm{ml} /$ minute within a short period of time (1 Hour). Several mechanisms are hypothesized to causes BP reduction after creation of AVF [100]. Reduction in total systemic vascular resistance, despite an increment of cardiac output is the main mechanism. Enhanced tissue oxygen delivery caused by increased arterial oxygen content may reduced peripheral and renal chemoreceptor activation and thus decrease sympathetic activity. Reduction in systemic vascular compliance and effective arterial volume may also improve arterial compliance, contributing to reduced cardiac work load, despite increased cardiac output [100]. In first randomized controlled trial of this technique at 6 month intervention group showed a reduction in office systolic BP of $27 \mathrm{mmHg}$ compared with a fall of $4 \mathrm{mmHg}$ in normal care group 
corroborated by ambulatory BP monitoring. Expected adverse effects are induction of venous stenosis and thrombosis and development of right HF so not used commonly.

\subsubsection{Renal artery Stenting}

Percutaneous transluminal angioplasty with Stenting for renal artery stenosis is controversial. The recent clinical trials revealed that little or no benefit for BP control, preservation of kidney function or prevention of $\mathrm{CV}$ or renal event with use of renal artery Stenting in hypertensive patient with renal artery stenosis [101] [102]. Angioplasty of fibromuscular lesion almost always benefits and often curative of associated hypertension and therefore recommended for treatment choice of hypertension. Poor controlled hypertension with CV risk then endovascular angioplasty with or without Stenting should be considered when drug therapy is unsuccessful. In ASTRAL trial renal artery revascularization did not result clinically relevant reduction in BP but cause high incidence of adverse procedure related complication so not used commonly.

\section{Conclusion}

Use lifestyle measure plus BP lowering drugs for secondary prevention of recurrent cardiovascular events in adults with clinical CVD (CHD, CHF and stroke) and an average systolic $\mathrm{BP} \geq 130 \mathrm{mmHg}$ or an average diastolic $\mathrm{BP} \geq 80 \mathrm{mmHg}$. The interventional BP lowering treatments performed in patients with TRH, is defined as a SBP $>160 \mathrm{mmHg}$ despite treatment with an average of 5 different antihypertensive drugs. There are two interventional approaches like Renal Denervation and Baroreflex activation therapy, which are most commonly used in clinical practice, and other interventional approaches like AVF, Renal artery Stenting are not used. The BP should be lower than $130 / 80 \mathrm{mmHg}$ in patients with diabetes mellitus, $\mathrm{CHF}, \mathrm{CKD}$, after renal transplantation and for secondary stroke prevention in lacunar stroke. A thiazide diuretics or ACE inhibitors or ARBs is started as a first agent to prescribe, with follow up BP and electrolyte measurement in 3 to 4 weeks. Dose increase or additional medication may be needed. We would recommend regular visits during dose adjustment; combined with home BP measurement, life style factors and medication adherences should be assessed at each visit. Once the BP is $<130 / 80 \mathrm{mmHg}$, we would recommend follow up at 6-month intervals.

\section{Acknowledgements}

This review article is supported by the National Natural Science Foundation of China (31700736), Hubei Province Natural Science Foundation of China (2016CFB180), Hubei Province Health and Family Planning Scientific Research Project (WJ2016Y07), Hubei Province Scientific and Technological Research Project (Q20171306), Jingzhou Science and Technology Development Planning Project (JZKJ15063) and the Yangtze Fund for Youth Teams of Science and Technology Innovation (2016CQT04). 


\section{Conflicts of Interest}

We declare that none of the authors have any financial and personal relationship with other people or organizations that can inappropriately influence the quality of the work present in the manuscript.

\section{References}

[1] Whelton, P.K., et al. (2018) 2017 ACC/AHA/AAPA/ABC/ACPM/AGS/APhA/ASH/ ASPC/NMA/PCNA Guideline for the Prevention, Detection, Evaluation, and Management of High Blood Pressure in Adults: A Report of the American College of Cardiology/American Heart Association Task Force on Clinical Practice Guidelines. Journal of the American College of Cardiology, 71, e127-e248.

https://doi.org/10.1016/j.jacc.2017.11.006

[2] Muntner, P., et al. (2018) Poten Itial US Population Impact of the 2017 ACC/AHA High Blood Pressure Guideline. Circulation, 137, 109-118.

https://doi.org/10.1161/CIRCULATIONAHA.117.032582

[3] Lim, S.S., et al. (2012) A Comparative Risk Assessment of Burden of Disease and Injury Attributable to 67 Risk Factors and Risk Factor Clusters in 21 Regions, 1990-2010: A Systematic Analysis for the Global Burden of Disease Study 2010. Lancet, 380, 2224-2260. https://doi.org/10.1016/S0140-6736(12)61766-8

[4] Lloyd-Jones, D., et al. (2009) Heart Disease and Stroke Statistics-2009 Update: A Report from the American Heart Association Statistics Committee and Stroke Statistics Subcommittee. Circulation, 119, 480-486.

https://doi.org/10.1161/CIRCULATIONAHA.108.191259

[5] Aronow, W.S., et al. (2009) A Propensity-Matched Study of the Association of Peripheral Arterial Disease with Cardiovascular Outcomes in Community-Dwelling Older Adults. American Journal of Cardiology, 103, 130-135.

https://doi.org/10.1016/j.amjcard.2008.08.037

[6] Aronow, W.S., et al. (2011) ACCF/AHA 2011 Expert Consensus Document on Hypertension in the Elderly: A Report of the American College of Cardiology Foundation Task Force on Clinical Expert Consensus Documents. Circulation, 123, 2434-2506. https://doi.org/10.1161/CIR.0b013e31821daaf6

[7] Persell, S.D. (2011) Prevalence of Resistant Hypertension in the United States, 2003-2008. Hypertension, 57, 1076-1080. https://doi.org/10.1161/HYPERTENSIONAHA.111.170308

[8] Sim, J.J., et al. (2013) Characteristics of Resistant Hypertension in a Large, Ethnically Diverse Hypertension Population of an Integrated Health System. Mayo Clinic Proceedings, 88, 1099-1107. https://doi.org/10.1016/j.mayocp.2013.06.017

[9] Calhoun, D.A., et al. (2014) Refractory Hypertension: Determination of Prevalence, Risk Factors, and Comorbidities in a Large, Population-Based Cohort. Hypertension, 63, 451-458. https://doi.org/10.1161/HYPERTENSIONAHA.113.02026

[10] Tomaszewski, M., et al. (2014) High Rates of Non-Adherence to Antihypertensive Treatment Revealed by High-Performance Liquid Chromatography-Tandem Mass Spectrometry (HP LC-MS/MS) Urine Analysis. Heart, 100, 855-861. https://doi.org/10.1136/heartjnl-2013-305063

[11] Ceral, J., et al. (2011) Difficult-to-Control Arterial Hypertension or Uncooperative Patients? The Assessment of Serum Antihypertensive Drug Levels to Differentiate Non-Responsiveness from Non-Adherence to Recommended Therapy. Hypertension Research, 34, 87-90. https://doi.org/10.1038/hr.2010.183 
[12] Jung, O., et al. (2013) Resistant Hypertension? Assessment of Adherence by Toxicological Urine Analysis. Journal of Hypertension, 31, 766-774. https://doi.org/10.1097/HJH.0b013e32835e2286

[13] Brinker, S., et al. (2014) Therapeutic Drug Monitoring Facilitates Blood Pressure Control in Resistant Hypertension. Journal of the American College of Cardiology, 63, 834-835. https://doi.org/10.1016/j.jacc.2013.10.067

[14] Ettehad, D., et al. (2016) Blood Pressure Lowering for Prevention of Cardiovascular Disease and Death: A Systematic Review and Meta-Analysis. Lancet, 387, 957-967. https://doi.org/10.1016/S0140-6736(15)01225-8

[15] Wright Jr., J.T., et al. (2015) A Randomized Trial of Intensive versus Standard Blood-Pressure Control. New England Journal of Medicine, 373, 2103-2116. https://doi.org/10.1056/NEJMoa1511939

[16] James, P.A., et al. (2014) Evidence-Based Guideline for the Management of High Blood Pressure in Adults: Report from the Panel Members Appointed to the Eighth Joint National Committee (JNC 8). JAMA, 311, 507-520. https://doi.org/10.1001/jama.2013.284427

[17] Wright Jr., J.T., Fine, L.J., Lackland, D.T., Ogedegbe, G. and Dennison Himmelfarb, C.R. (2014) Evidence Supporting a Systolic Blood Pressure Goal of Less than 150 $\mathrm{mmHg}$ in Patients Aged 60 Years or Older: The Minority View. Annals of Internal Medicine, 160, 499-503. https://doi.org/10.7326/M13-2981

[18] Jaques, H. (2013) NICE Guideline on Hypertension. European Heart Journal, 34, 406-408.

[19] Weber, M.A., et al. (2014) Clinical Practice Guidelines for the Management of Hypertension in the Community: A Statement by the American Society of Hypertension and the International Society of Hypertension. Journal of Clinical Hypertension, 16, 14-26. https://doi.org/10.1111/jch.12237

[20] Rosendorff, C., et al. (2015) Treatment of Hypertension in Patients with Coronary Artery Disease: A Scientific Statement from the American Heart Association, American College of Cardiology, and American Society of Hypertension. Journal of the American College of Cardiology, 65, 1998-2038.

https://doi.org/10.1016/j.jacc.2015.02.038

[21] Gabb, G.M., et al. (2016) Guideline for the Diagnosis and Management of Hypertension in Adults-2016. Medical Journal of Australia, 205, 85-89. https://doi.org/10.5694/mja16.00526

[22] Qaseem, A., et al. (2017) Pharmacologic Treatment of Hypertension in Adults Aged 60 Years or Older to Higher Versus Lower Blood Pressure Targets: A Clinical Practice Guideline from the American College of Physicians and the American Academy of Family Physicians. Annals of Internal Medicine, 166, 430-437. https://doi.org/10.7326/M16-1785

[23] Whelton, P.K., Carey, R.M., Aronow, W.S., Casey Jr., D.E., Collins, K.J., et al. (2018) 2017 ACC/AHA/AAPA/ABC/ACPM/AGS/APhA/ASH/ASPC/NMA/PCNA Guideline for the Prevention, Detection, Evaluation, and Management of High Blood Pressure in Adults: A Report of the American College of Cardiology/American Heart Association Task Force on Clinical Practice Guidelines. Hypertension, 71, e13-e115.

[24] Aronow, W.S. (2017) Lifestyle Measures for Treating Hypertension. Archives of Medical Science, 13, 1241-1243. https://doi.org/10.5114/aoms.2017.68650

[25] Thompson, A.M., et al. (2011) Antihypertensive Treatment and Secondary Prevention of Cardiovascular Disease Events among Persons without Hypertension: A 
Meta-Analysis. JAMA, 305, 913-922. https://doi.org/10.1001/jama.2011.250

[26] Czernichow, S., et al. (2011) The Effects of Blood Pressure Reduction and of Different Blood Pressure-Lowering Regimens on Major Cardiovascular Events according to Baseline Blood Pressure: Meta-Analysis of Randomized Trials. Journal of Hypertension, 29, 4-16. https://doi.org/10.1097/HJH.0b013e32834000be

[27] Goff Jr., D.C., et al. (2014) 2013 ACC/AHA Guideline on the Assessment of Cardiovascular Risk: A Report of the American College of Cardiology/American Heart Association Task Force on Practice Guidelines. Journal of the American College of Cardiology, 63, 2935-2959. https://doi.org/10.1016/j.jacc.2013.11.005

[28] Williamson, J.D., et al. (2016) Intensive vs Standard Blood Pressure Control and Cardiovascular Disease Outcomes in Adults Aged $\geq 75$ Years: A Randomized Clinical Trial. JAMA, 315, 2673-2682. https://doi.org/10.1001/jama.2016.7050

[29] The Blood Pressure Lowering Treatment Trialists' Collaboration (2014) Blood Pressure-Lowering Treatment Based on Cardiovascular Risk: A Meta-Analysis of Individual Patient Data. The Lancet, 384, 591-598. https://doi.org/10.1016/S0140-6736(14)61212-5

[30] Lewington, S., et al. (2002) Age-Specific Relevance of Usual Blood Pressure to Vascular Mortality: A Meta-Analysis of Individual Data for One Million Adults in 61 Prospective Studies. The Lancet, 360, 1903-1913.

https://doi.org/10.1016/S0140-6736(02)11911-8

[31] Bundy, J.D., et al. (2017) Systolic Blood Pressure Reduction and Risk of Cardiovascular Disease and Mortality: A Systematic Review and Network Meta-analysis. JAMA Cardiology, 2, 775-781. https://doi.org/10.1001/jamacardio.2017.1421

[32] Yancy, C.W., et al. (2017) 2017 ACC/AHA/HFSA Focused Update of the 2013 ACCF/AHA Guideline for the Management of Heart Failure: A Report of the American College of Cardiology/American Heart Association Task Force on Clinical Practice Guidelines and the Heart Failure Society of America. Journal of the American College of Cardiology, 70, 776-803. https://doi.org/10.1016/j.jacc.2017.04.025

[33] Upadhyay, A., Earley, A., Haynes, S.M. and Uhlig, K. (2011) Systematic Review: Blood Pressure Target in Chronic Kidney Disease and Proteinuria as an Effect Modifier. Annals of Internal Medicine, 154, 541-548. https://doi.org/10.7326/0003-4819-154-8-201104190-00335

[34] Benavente, O.R., et al. (2013) Blood-Pressure Targets in Patients with Recent Lacunar Stroke: The SPS3 Randomised Trial. The Lancet, 382, 507-515. https://doi.org/10.1016/S0140-6736(13)60852-1

[35] Emdin, C.A., et al. (2015) Blood Pressure Lowering in Type 2 Diabetes: A Systematic Review and Meta-Analysis. JAMA, 313, 603-615. https://doi.org/10.1001/jama.2014.18574

[36] Aronow, W.S. (2016) Orthostatic Hypotension in Diabetics in the ACCORD (Action to Control Cardiovascular Risk in Diabetes) Blood Pressure Trial. Hypertension, 68, 851-852. https://doi.org/10.1161/HYPERTENSIONAHA.116.07605

[37] Wang, W.T., et al. (2016) Comparative Effectiveness of Blood Pressure-Lowering Drugs in Patients Who Have Already Suffered from Stroke: Traditional and Bayesian Network Meta-Analysis of Randomized Trials. Medicine, 95, e3302. https://doi.org/10.1097/MD.0000000000003302

[38] Pedrosa, R.P., et al. (2011) Obstructive Sleep Apnea: The Most Common Secondary Cause of Hypertension Associated with Resistant Hypertension. Hypertension, 58, 811-817. https://doi.org/10.1161/HYPERTENSIONAHA.111.179788 
[39] Schwartz, G.L. and Turner, S.T. (2005) Screening for Primary Aldosteronism in Essential Hypertension: Diagnostic Accuracy of the Ratio of Plasma Aldosterone Concentration to Plasma Renin Activity. Clinical Chemistry, 51, 386-394. https://doi.org/10.1373/clinchem.2004.041780

[40] Sawka, A.M., Jaeschke, R., Singh, R.J. and Young, W.F. (2003) A Comparison of Biochemical Tests for Pheochromocytoma: Measurement of Fractionated Plasma Metanephrines Compared with the Combination of 24-Hour Urinary Metanephrines and Catecholamines. Journal of Clinical Endocrinology and Metabolism, 88, 553-558. https://doi.org/10.1210/jc.2002-021251

[41] Oliveras, A., et al. (2010) Urinary Albumin Excretion Is Associated with True Resistant Hypertension. Journal of Human Hypertension, 24, 27-33. https://doi.org/10.1038/jhh.2009.35

[42] Calhoun, D.A., et al. (2008) Resistant Hypertension: Diagnosis, Evaluation, and Treatment. A Scientific Statement from the American Heart Association Professional Education Committee of the Council for High Blood Pressure Research. Hypertension, 51, 1403-1419. https://doi.org/10.1161/HYPERTENSIONAHA.108.189141

[43] De la Sierra, A., et al. (2012) Clinical Differences between Resistant Hypertensives and Patients Treated and Controlled with Three or Less Drugs. Journal of Hypertension, 30, 1211-1216. https://doi.org/10.1097/HJH.0b013e328353634e

[44] Campese, V.M., Mitra, N. and Sandee, D. (2006) Hypertension in Renal Parenchymal Disease: Why Is It So Resistant to Treatment? Kidney International, 69, 967-973. https://doi.org/10.1038/sj.ki.5000177

[45] Aburto, N.J., et al. (2013) Effect of Lower Sodium Intake on Health: Systematic Review and Meta-Analyses. BMJ, 346, f1326. https://doi.org/10.1136/bmj.f1326

[46] He, F.J., Li, J. and Macgregor, G.A. (2013) Effect of Longer Term Modest Salt Reduction on Blood Pressure: Cochrane Systematic Review and Meta-Analysis of Randomised Trials. BMJ, 346, f1325. https://doi.org/10.1136/bmj.f1325

[47] Neter, J.E., et al. (2003) Influence of Weight Reduction on Blood Pressure: A Meta-Analysis of Randomized Controlled Trials. Hypertension, 42, 878-884. https://doi.org/10.1161/01.HYP.0000094221.86888.AE

[48] Cornelissen, V.A. and Smart, N.A. (2013) Exercise Training for Blood Pressure: A Systematic Review and Meta-Analysis. Journal of the American Heart Association, 2, e004473. https://doi.org/10.1161/JAHA.112.004473

[49] Carlson, D.J., et al. (2014) Isometric Exercise Training for Blood Pressure Management: A Systematic Review and Meta-Analysis. Mayo Clinic Proceedings, 89, 327-334. https://doi.org/10.1016/j.mayocp.2013.10.030

[50] Xin, X., et al. (2001) Effects of Alcohol Reduction on Blood Pressure: A Meta-Analysis of Randomized Controlled Trials. Hypertension, 38, 1112-1127. https://doi.org/10.1161/hy1101.093424

[51] Roerecke, M., et al. (2017) The effect of a Reduction in Alcohol Consumption on Blood Pressure: A Systematic Review and Meta-Analysis. Lancet Public Health, 2, e108-e120. https://doi.org/10.1016/S2468-2667(17)30003-8

[52] Whelton, P.K., et al. (1997) Effects of Oral Potassium on Blood Pressure. Meta-Analysis of Randomized Controlled Clinical Trials. JAMA, 277, 1624-1632. https://doi.org/10.1001/jama.1997.03540440058033

[53] The Antihypertensive and Lipid-Lowering Treatment to Prevent Heart Attack Trial (ALLHAT) (2002) Major Outcomes in High-Risk Hypertensive Patients Rando- 
mized to Angiotensin-Converting Enzyme Inhibitor or Calcium Channel Blocker vs Diuretic:. JAMA, 288, 2981-2997.

https://doi.org/10.1001/jama.288.23.2981

[54] Law, M.R., Morris, J.K. and Wald, N.J. (2009) Use of Blood Pressure Lowering Drugs in the Prevention of Cardiovascular Disease: Meta-Analysis of 147 Randomised Trials in the Context of Expectations from Prospective Epidemiological Studies. BMJ, 338, b1665. https://doi.org/10.1136/bmj.b1665

[55] Smith Jr., S.C., et al. (2011) AHA/ACCF Secondary Prevention and Risk Reduction Therapy for Patients with Coronary and other Atherosclerotic Vascular Disease: 2011 Update: A Guideline from the American Heart Association and American College of Cardiology Foundation. Circulation, 124, 2458-2473. https://doi.org/10.1161/CIR.0b013e318235eb4d

[56] Aronow, W.S. (2010) Current Role of Beta-Blockers in the Treatment of Hypertension. Expert Opinion on Pharmacotherapy, 11, 2599-2607. https://doi.org/10.1517/14656566.2010.482561

[57] Pitt, B., et al. (2005) Eplerenone Reduces Mortality 30 Days after Randomization Following Acute Myocardial Infarction in Patients with Left Ventricular Systolic Dysfunction and Heart Failure. Journal of the American College of Cardiology, 46, 425-431. https://doi.org/10.1016/j.jacc.2005.04.038

[58] MERIT-HF Study Group (1999) Effect of Metoprolol CR/XL in Chronic Heart Failure: Metoprolol CR/XL Randomised Intervention Trial in Congestive Heart Failure (MERIT-HF). The Lancet, 353, 2001-2007. https://doi.org/10.1016/S0140-6736(99)04440-2

[59] Packer, M., et al. (2001) Effect of Carvedilol on Survival in Severe Chronic Heart Failure. New England Journal of Medicine, 344, 1651-1658. https://doi.org/10.1056/NEJM200105313442201

[60] CIBIS-II Investigators and Committees (1999) The Cardiac Insufficiency Bisoprolol Study II (CIBIS-II): A Randomised Trial. The Lancet, 353, 9-13. https://doi.org/10.1016/S0140-6736(98)11181-9

[61] Aronow, W.S., Ahn, C. and Kronzon, I. (1997) Effect of Propranolol versus No Propranolol on Total Mortality Plus Nonfatal Myocardial Infarction in Older Patients with Prior Myocardial Infarction, Congestive Heart Failure, and Left Ventricular Ejection Fraction $\geq 40 \%$ Treated with Diuretics Plus Angiotensin-Converting Enzyme Inhibitors. American Journal of Cardiology, 80, 207-209. https://doi.org/10.1016/S0002-9149(97)00320-2

[62] Pfeffer, M.A., et al. (2015) Regional Variation in Patients and Outcomes in the Treatment of Preserved Cardiac Function Heart Failure with an Aldosterone Antagonist (TOPCAT) Trial. Circulation, 131, 34-42. https://doi.org/10.1161/CIRCULATIONAHA.114.013255

[63] Wright Jr., J.T., et al. (2002) Effect of Blood Pressure Lowering and Antihypertensive Drug Class on Progression of Hypertensive Kidney Disease: Results from the AASK Trial. JAMA, 288, 2421-2431. https://doi.org/10.1001/jama.288.19.2421

[64] Jafar, T.H., et al. (2003) Progression of Chronic Kidney Disease: The Role of Blood Pressure Control, Proteinuria, and Angiotensin-Converting Enzyme Inhibition: A Patient-Level Meta-Analysis. Annals of Internal Medicine, 139, 244-252. https://doi.org/10.7326/0003-4819-139-4-200308190-00006

[65] Appel, L.J., et al. (2010) Intensive Blood-Pressure Control in Hypertensive Chronic Kidney Disease. New England Journal of Medicine, 363, 918-929. https://doi.org/10.1056/NEJMoa0910975 
[66] Cross, N.B., et al. (2009) Antihypertensives for Kidney Transplant Recipients: Systematic Review and Meta-Analysis of Randomized Controlled Trials. Transplantation, 88, 7-18. https://doi.org/10.1097/TP.0b013e3181a9e960

[67] PROGRESS Collaborative Group (2001) Randomised Trial of a Perindopril-Based Blood-Pressure-Lowering Regimen among 6,105 Individuals with Previous Stroke or Transient Ischaemic Attack. The Lancet, 358, 1033-1041. https://doi.org/10.1016/S0140-6736(01)06178-5

[68] Liu, L., et al. (2009) Blood Pressure Reduction for the Secondary Prevention of Stroke: A Chinese Trial and a Systematic Review of the Literature. Hypertension Research, 32, 1032-1040. https://doi.org/10.1038/hr.2009.139

[69] Lakhan, S.E. and Sapko, M.T. (2009) Blood Pressure Lowering Treatment for Preventing Stroke Recurrence: A Systematic Review and Meta-Analysis. International Archives of Medicine, 2, 30. https://doi.org/10.1186/1755-7682-2-30

[70] Bavry, A.A., et al. (2010) Outcomes among Hypertensive Patients with Concomitant Peripheral and Coronary Artery Disease: Findings from the International VErapamil-SR/Trandolapril Study. Hypertension, 55, 48-53. https://doi.org/10.1161/HYPERTENSIONAHA.109.142240

[71] Turnbull, F., et al. (2005) Effects of Different Blood Pressure-Lowering Regimens on Major Cardiovascular Events in Individuals with and without Diabetes Mellitus: Results of Prospectively Designed Overviews of Randomized Trials. Archives of Internal Medicine, 165, 1410-1419. https://doi.org/10.1001/archinte.165.12.1410

[72] Palmer, S.C., et al. (2015) Comparative Efficacy and Safety of Blood Pressure-Lowering Agents in Adults with Diabetes and Kidney Disease: A Network Meta-Analysis. The Lancet, 385, 2047-2056. https://doi.org/10.1016/S0140-6736(14)62459-4

[73] Schmieder, R.E., et al. (2007) Renin-Angiotensin System and Cardiovascular Risk. The Lancet, 369, 1208-1219. https://doi.org/10.1016/S0140-6736(07)60242-6

[74] Suzuki, T., et al. (2012) Type-Selective Benefits of Medications in Treatment of Acute Aortic Dissection (from the International Registry of Acute Aortic Dissection [IRAD]). American Journal of Cardiology, 109, 122-127. https://doi.org/10.1016/j.amjcard.2011.08.012

[75] Pucci, M., et al. (2015) Angiotensin-Converting Enzyme Inhibitors and Angiotensin Receptor Blockers in Women of Childbearing Age: Risks versus Benefits. Expert Review of Clinical Pharmacology, 8, 221-231. https://doi.org/10.1586/17512433.2015.1005074

[76] Ferrer, R.L., et al. (2000) Management of Mild Chronic Hypertension during Pregnancy: A Review. Obstetrics \& Gynecology, 96, 849-860.

[77] Moretti, M.E., et al. (2012) The Fetal Safety of Angiotensin Converting Enzyme Inhibitors and Angiotensin II Receptor Blockers. Obstetrics and Gynecology International, 2012, Article ID: 658310. https://doi.org/10.1155/2012/658310

[78] James, P.R. and Nelson-Piercy, C. (2004) Management of Hypertension before, during, and after Pregnancy. Heart, 90, 1499-1504.

https://doi.org/10.1136/hrt.2004.035444

[79] Tataru, A.P. and Barry, A.R. (2017) A Systematic Review of Add-On Pharmacologic Therapy in the Treatment of Resistant Hypertension. American Journal of Cardiovascular Drugs, 17, 311-318. https://doi.org/10.1007/s40256-017-0224-5

[80] Ruilope, L.M. (2008) Aldosterone, Hypertension, and Cardiovascular Disease: An Endless Story. Hypertension, 52, 207-208.

https://doi.org/10.1161/HYPERTENSIONAHA.108.111211 
[81] Kawamoto, T., et al. (1992) Role of Steroid 11 Beta-Hydroxylase and Steroid 18-Hydroxylase in the Biosynthesis of Glucocorticoids and Mineralocorticoids in Humans. Proceedings of the National Academy of Sciences of the United States of America, 89, 1458-1462. https://doi.org/10.1073/pnas.89.4.1458

[82] Fagart, J., et al. (2010) A New Mode of Mineralocorticoid Receptor Antagonism by a Potent and Selective Nonsteroidal Molecule. Journal of Biological Chemistry, 285, 29932-29940. https://doi.org/10.1074/jbc.M110.131342

[83] Barfacker, L., et al. (2012) Discovery of BAY 94-8862: A Nonsteroidal Antagonist of the Mineralocorticoid Receptor for the Treatment of Cardiorenal Diseases. ChemMedChem, 7, 1385-1403. https://doi.org/10.1002/cmdc.201200081

[84] Kolkhof, P., et al. (2014) Finerenone, a Novel Selective Nonsteroidal Mineralocorticoid Receptor Antagonist Protects from Rat Cardiorenal Injury. Journal of Cardiovascular Pharmacology, 64, 69-78. https://doi.org/10.1097/FJC.0000000000000091

[85] Menard, J., Marie-Françoise, G., Thanh-Tam, G. and Alvine, B. (2006) Investigation of Aldosterone-Synthase Inhibition in Rats. Journal of Hypertension, 24, 1147-1155. https://doi.org/10.1097/01.hjh.0000226205.65442.f2

[86] Lea, W.B., et al. (2009) Aldosterone Antagonism or Synthase Inhibition Reduces End-Organ Damage Induced by Treatment with Angiotensin and High Salt. Kidney International, 75, 936-944. https://doi.org/10.1038/ki.2009.9

[87] Menard, J., et al. (2014) Aldosterone Synthase Inhibition: Cardiorenal Protection in Animal Disease Models and Translation of Hormonal Effects to Human Subjects. Journal of Translational Medicine, 12, 340. https://doi.org/10.1186/s12967-014-0340-9

[88] Amar, L., et al. (2010) Aldosterone Synthase Inhibition with LCI699: A Proof-of-Concept Study in Patients with Primary Aldosteronism. Hypertension, 56, 831-838. https://doi.org/10.1161/HYPERTENSIONAHA.110.157271

[89] Calhoun, D.A., et al. (2011) Effects of a Novel Aldosterone Synthase Inhibitor for Treatment of Primary Hypertension: Results of a Randomized, Double-Blind, Placebo- and Active-Controlled Phase 2 Trial. Circulation, 124, 1945-1955. https://doi.org/10.1161/CIRCULATIONAHA.111.029892

[90] Corti, R., Burnett Jr., J.C., Rouleau, J.L., Ruschitzka, F. and Lüscher, T.F. (2001) Vasopeptidase Inhibitors: A New Therapeutic Concept in Cardiovascular Disease? Circulation, 104, 1856-1862. https://doi.org/10.1161/hc4001.097191

[91] Edelson, J.D., Makhlina, M., Silvester, K.R., Vengurlekar, S.S., Chen, X.M., et al. (2013) In Vitro and in Vivo Pharmacological Profile of PL-3994, a Novel Cyclic Peptide (Hept-cyclo(Cys-His-Phe-d-Ala-Gly-Arg-d-Nle-Asp-Arg-Ile-Ser-Cys)-Tyr-[Arg mimetic] $-\mathrm{NH}_{2}$ ) Natriuretic Peptide Receptor-A Agonist That Is Resistant to Neutral Endopeptidase and Acts as a Bronchodilator. Pulmonary Pharmacology and Therapeutics, 26, 229-238. https://doi.org/10.1016/j.pupt.2012.11.001

[92] Almeida, L., et al. (2013) Etamicastat, a Novel Dopamine Beta-Hydroxylase Inhibitor: Tolerability, Pharmacokinetics, and Pharmacodynamics in Patients with Hypertension. Clinical Therapeutics, 35, 1983-1996. https://doi.org/10.1016/j.clinthera.2013.10.012

[93] Esler, M., et al. (1988) Assessment of Human Sympathetic Nervous System Activity from Measurements of Norepinephrine Turnover. Hypertension, 11, 3-20. https://doi.org/10.1161/01.HYP.11.1.3

[94] DiBona, G.F. and Kopp, U.C. (1997) Neural Control of Renal Function. Physiological Reviews, 77, 75-197. https://doi.org/10.1152/physrev.1997.77.1.75

[95] Esler, M.D., et al. (2010) Renal Sympathetic Denervation in Patients with Treat- 
ment-Resistant Hypertension (The Symplicity HTN-2 Trial): A Randomised Controlled Trial. The Lancet, 376, 1903-1909.

https://doi.org/10.1016/S0140-6736(10)62039-9

[96] Schmieder, R.E., et al. (2012) ESH Position Paper: Renal Denervation-An Interventional Therapy of Resistant Hypertension. Journal of Hypertension, 30, 837-841. https://doi.org/10.1097/HJH.0b013e328352ce78

[97] Bisognano, J.D., et al. (2011) Baroreflex Activation Therapy lowers Blood Pressure in Patients with Resistant Hypertension: Results from the Double-Blind, Randomized, Placebo-Controlled Rheos Pivotal Trial. Journal of the American College of Cardiology, 58, 765-773. https://doi.org/10.1016/j.jacc.2011.06.008

[98] Scheffers, I.J., et al. (2010) Novel Baroreflex Activation Therapy in Resistant Hypertension: Results of a European Multi-Center Feasibility Study. Journal of the American College of Cardiology, 56, 1254-1258. https://doi.org/10.1016/j.jacc.2010.03.089

[99] Sinski, M., et al. (2012) Tonic Activity of Carotid Body Chemoreceptors Contributes to the Increased Sympathetic Drive in Essential Hypertension. Hypertension Research, 35, 487-491. https://doi.org/10.1038/hr.2011.209

[100] Burchell, A.E., Lobo, M.D., Sulke, N., Sobotka, P.A. and Paton, J.F.R. (2014) Arteriovenous Anastomosis: Is This the Way to Control Hypertension? Hypertension, 64, 6-12. https://doi.org/10.1161/HYPERTENSIONAHA.114.02925

[101] Bax, L., et al. (2009) Stent Placement in Patients with Atherosclerotic Renal Artery Stenosis and Impaired Renal Function: A Randomized Trial. Annals of Internal Medicine, 150, 840-848.

https://doi.org/10.7326/0003-4819-150-12-200906160-00119

[102] Wheatley, K., et al. (2009) Revascularization versus Medical Therapy for Renal-Artery Stenosis. New England Journal of Medicine, 361, 1953-1962. https://doi.org/10.1056/NEJMoa0905368 


\section{Abbreviations}

BP: Blood pressure.

SBP: Systolic blood pressure.

DBP: Diastolic blood pressure.

AV: Atrioventricular.

ACC: American college of cardiology.

AHA: American heart association.

TLC: Total leukocytes counts.

DLC: Differential leukocytes counts.

HB: Hemoglobin.

RBC: Red blood cells counts.

MRA: Mineralocorticoid receptor antagonist.

MR: Mineralocorticoid receptor.

RDN: Renal denervation.

AVF: Arteriovenous Fistula.

$\mathrm{RH}$ : Resistant hypertension.

CVD: Cardiovascular disease.

LVH: Left ventricular hypertrophy.

TIA: Transient Ischemic attack.

SCD: Sudden cardiac death.

PAD: Peripheral arterial disease.

CHD: Coronary heart disease.

CHF: Congestive heart failure.

MI: Myocardial infarction.

CKD: Chronic kidney disease.

CCB: Calcium channel blockers.

ACE: Angiotensin converting enzyme.

ARB: Angiotensin receptors blockers.

TRH: Treatment resistant hypertension. 